\title{
Overexpression of CD55 correlates with tumor progression and poor prognosis in gastric stromal tumors
}

Xiaonan Yin ${ }^{l, *}$

Chaoyong Shen ${ }^{1} *$

Yuan Yin'

Zhaolun Cai ${ }^{1}$

Jian Wang'

Zhou Zhao'

Xin Chen'

Zhixin Chen'

Huijiao Chen ${ }^{2}$

Bo Zhang'

'Department of Gastrointestinal Surgery, West China Hospital, Sichuan University, Chengdu, Sichuan 6I004I, People's Republic of China; ${ }^{2}$ Department of Pathology, West China Hospital, Sichuan University, Chengdu, Sichuan 61004I,

People's Republic of China

*These authors contributed equally to this work
This article was published in the following Dove Press journal: OncoTargets and Therapy

Backgrounds: Accumulating evidences have demonstrated that CD55 can protect cells from complement-mediated attack, and is involved in tumor dedifferentiation, migration, invasiveness, and metastasis. However, the role of CD55 in gastrointestinal stromal tumors (GISTs) has not been investigated.

Aims: Our study aimed to analyze the expression of CD55 in gastric GISTs and its correlations with clinicopathologic characteristics and prognosis.

Materials and methods: A total of 118 gastric GIST patients were included in our study. CD55 expression in GIST tissue samples was evaluated using immunohistochemistry. Cumulative survival was conducted using the Kaplan-Meier method. Cox regression analyses were performed to identify factors associated with progression-free survival (PFS) for patients with gastric GISTs.

Results: Of 118 gastric GISTs patients included in our study, 44 (37.3\%) were positive for CD55 expression. Positive CD55 expression in gastric GISTs was closely associated with tumor size $(13.52 \pm 7.35$ vs $5.07 \pm 1.90 \mathrm{~cm}$, respectively; $P<0.001)$, Ki 67 labeling index $(P=0.001)$, mitotic counts $(P=0.005)$, NIH risk classification $(P<0.001)$, PLR $(P<0.001)$, and metastasis at initial diagnosis $(P=0.002)$. Kaplan-Meier analyses revealed that tumor size $(P<0.001)$, mitotic counts $(P<0.001)$, Ki 67 labeling index $(P<0.001)$, PLR $(P<0.001)$, metastasis at initial diagnosis $(P=0.031)$, and CD55 expression $(P<0.001)$ were statistically significant risk factors affecting PFS of patients with gastric GISTs. Cox multivariate survival analysis showed that mitotic counts, Ki 67 labeling index, and CD55 expression were independent predictors of PFS for gastric GISTs.

Conclusion: CD55 may be a potential prognostic marker in gastric GISTs patients.

Keywords: CD55, gastrointestinal stromal tumor, prognosis

\section{Introduction}

Gastrointestinal stromal tumors (GISTs) are the most common mesenchymal tumors of the gastrointestinal tract. It is recognized as originating from intestinal cells of Cajal or their precursors and is characterized by the gain-of-function mutations of KIT and platelet-derived growth factor receptor- $\alpha$ (PDGFRA) gene. ${ }^{1-3}$ GISTs are clinically heterogeneous, and half of the patients experience tumor recurrence or metastasis after complete resection, usually within 2 years of resection. ${ }^{4,5}$ Imatinib, a small-molecule tyrosine kinase inhibitor (TKI) that blocks the activity of receptor tyrosine kinases, KIT or PDGFRA, has revolutionized the treatment of GIST. In patients with advanced, inoperable, or high-risk GISTs, imatinib achieves significant improvement of the 
progression-free survival (PFS) and overall survival. Unfortunately, with time most patients experience disease progression or acquired resistance during targeted treatment. ${ }^{6,7}$ Therefore, it is important to explore the biology mechanism of GIST and discover new therapeutic targets for this tumor.

Several prognostic models for assessing the malignant potential of GIST have been proposed in recent 20 years, which mainly comprise clinical factors such as tumor size, mitotic count, tumor location, and presence of tumor rupture. ${ }^{8-11}$ However, these existing risk classification criteria cannot accurately predict the prognosis of GISTs, and the intrinsic mechanism of clinical aggressiveness of GIST is still undefined. Recently, a series of studies have reported that many molecular biomarkers are associated with the development and progression of GISTs, including tumor suppressors PTEN, P53, CD9, and tumor promoters CD133, Ki67, MMP-9. ${ }^{12-20}$

In our previous study, ${ }^{21}$ we compared the gastric GIST tissues of low-grade malignance (tumor size $\leq 2 \mathrm{~cm}$ and mitotic rate $\leq 5$ mitoses/50 HPFs) with those of high-grade malignance (tumor size $>2 \mathrm{~cm}$ and mitotic rate $>10$ mitoses/50 HPFs) using protein microarray analysis, with the aim of identifying the candidate proteins associated with the malignant biological potential of GISTs. And a list of differentially expressed proteins between low- and highgrade malignant gastric GISTs were detected. We found a potentially novel candidate protein CD55 was markedly upregulated in gastric GIST of high-grade malignancy when compared to those of low-grade malignancy $(P=0.015)$. Hence, we hypothesized that CD55 protein might be involved with the prognosis of gastric GISTs (Figure S1). CD55 is known as complement decay accelerating factor and is a glycosylphosphatidylinositol-anchored protein that regulates complement system activation. CD55 plays a role in protecting cells from complement-mediated attack by binding to $\mathrm{C} 3$ convertases from both the classic and alternative complement pathways, preventing $\mathrm{C} 3 \mathrm{~b}$ deposition and inhibiting the formation of the membrane attack complex. Complement attack is a powerful innate mechanism in the protection of the host against pathogens, including cancer. A number of studies have demonstrated that CD55 is involved in tumor dedifferentiation, migration, invasiveness, and metastasis, and is overexpressed in various cancers. ${ }^{22-25}$ Furthermore, several studies suggest that the overexpression of CD55 is an independent factor for poor prognosis and is associated with metastatic progression in many cancers including gastric cancer and breast cancer. ${ }^{26,27}$ However, the expression and potential role of CD55 in the initiation and progression of GISTs have not been reported yet.

Therefore, in this study, based on data obtained from 118 consecutive patients with gastric GISTs in our institution, we aimed to investigate the expression and clinicopathological significance of CD55 in gastric GISTs, as well as to explore its potential value as a prognostic marker in gastric GISTs patients.

\section{Materials and methods \\ Patients}

This study was approved by the Research Ethics Board of West China Hospital, Sichuan University and was conducted in accordance with the Declaration of Helsinki. Written informed consent was obtained from all patient included in this study. A total of 118 gastric GISTs patients were consecutively involved at the department of gastrointestinal surgery, West China Hospital, Sichuan University between January 2008 and July 2017. Eligible patients met the following criteria: all primary gastric GISTs were confirmed by postoperative pathological and immunohistochemical analyses; patients underwent surgical resection; patients with complete medical records. Patients with the following conditions were excluded: patients received preoperative chemotherapy and/or radiotherapy; patients with serve disease of other systems or coexistence of any other malignancies. Furthermore, due to the role of CD55 involved in the interaction with complement, it would be interesting to see whether other features that could suggest an enhanced systemic inflammatory response, such as perioperative high neutrophil-tolymphocyte ratio (NLR) or platelet-to-lymphocyte ratio (PLR) would also add up to the negative prognostic role of CD55. Hence, for all enrolled patients, clinicopathological parameters including patient demographics, tumor size, tumor location, mitotic count, ki67 labeling index, laboratory data (neutrophil, lymphocyte, and platelet counts) of the patients within one week prior to surgery, metastasis at initial diagnosis, NIH risk classification were retrieved from patients' medical records. In this study, the cutoff values of the NLR and PLR were set at 2.24 and 141.29 , respectively, based on the study conducted by Feng et al. ${ }^{28}$ The patients were then divided into two groups: high and low NLR groups, high and low PLR groups. 


\section{Immunohistochemistry analysis}

Immunohistochemistry staining for CD55 was performed on 4- $\mu \mathrm{m}$-thick sections of the paraffin-embedded tissues using the avidin-biotin-peroxidase complex method.

Briefly, these sections were deparaffinized in xylene and dehydrated in gradually decreasing concentrations of alcohol to water. Then, the tissue sections underwent heat-induced antigen retrieval at $95^{\circ} \mathrm{C}$ for 15 mins while immersed in citrate buffer ( $\mathrm{pH}$ 6.0). Endogenous peroxidase activity was blocked with $3 \%$ hydrogen peroxidase for 30 mins. Next, phosphate-buffered saline (PBS) containing $5 \mathrm{~g} / \mathrm{L}$ bovine serum albumin was utilized to block nonspecific antibody binding. The specimens were then incubated with a 1:100 dilution of the primary antibody against CD55 (ab133684, Abcam, United Kingdom) overnight at $4^{\circ} \mathrm{C}$. After incubation, the specimens were washed three times with PBS and then were incubated with a secondary antibody. The specimens were stained with diaminobenzidine (Dako) and finally were counterstained with hematoxylin. Negative controls were performed by replacing the primary antibody with nonimmune immunoglobulin. Immunostaining was scored blindly by two independent pathologists using an Olympus CX31 microscope (Olympus, Center Valley, PA), who were blinded to clinicopathological parameters of each sample. CD55 expression was identified as the existence of yellow-brown membrane staining of tumor cells. The percentage of positive cells was calculated as $0(<10 \%), 1(10-50 \%), 2(51-75 \%)$, $3(>76 \%)$. And the intensity of staining was scored as 0 (negative), 1 (weak), 2 (moderate), 3 (strong). A final score was counted from the percentage staining score $x$ intensity score, ranging from 0 to 9 . Therefore, tumors with a total score exceeding 3 were defined as a positive expression of CD55, otherwise were considered to be negative. The expression level of CD55 was analyzed by determining the integral optical density (IOD) of the signal. The IOD of each slide (original magnification $400 \times$ ) covering the entire tissue specimen was quantitatively assessed by using Image-Pro Plus version 7.0 (Media Cybernetics, Inc, USA) software.

\section{Follow-up}

Ultrasonography and/or computed tomography of the whole abdomen was performed every 3-6 months after surgery. Follow-up data including postoperative imatinib therapy, tumor recurrence, and/or metastasis, death events were collected by telephone call or the outpatient clinic visit. PFS was defined as the date from surgery to the date of first disease progression, patients alive without progression at the time of data collection were censored. OS was calculated from the date of surgery to the date of death, patients who were alive were censored.

\section{Statistical analysis}

SPSS for Windows Version 19.0 (SPSS Inc, IL, USA) was used for statistical analysis. Categorical variables were presented as percentages and were analyzed using the Chisquared or Fisher's exact tests. Continuous variables were expressed as mean \pm standard deviation (SD). One-way analysis of variance was applied to two-sided pair-wise multiple comparisons. Cumulative survival was conducted using the Kaplan-Meier method and log-rank test. Univariate and multivariate cox proportional hazards model were performed to explore independent prognostic factors. A two-sided $P$-value $<0.05$ was considered statistically significant.

\section{Results}

\section{Patient characteristics}

A total of 118 patients with gastric GIST were included in our study, there were 61 males and 57 females, with a mean age of $55.66 \pm 12.47$ years and a median age of 57.0 years (range, $13-84$ years). The mean tumor size was $8.22 \pm 6.24 \mathrm{~cm}$ and with a median size of $6 \mathrm{~cm}$ (range, 2-40 cm). Tumor sites were mainly located in the upper third and low third of the stomach, and all patients underwent radical resection (R0). Immunohistochemical staining for CD117, CD34, and DOG-1 protein was positive in 110 (93.2\%), 106 (89.8\%), and 114 (96.6\%) cases, respectively. The cohort study of 118 patients included 4 very low-risk, 25 low-risk, 34 intermediate-risk, and 55 highrisk patients according to the NIH classification. Of these patients, 17 patients had hepatic and/or peritoneal metastasis at initial diagnosis. A total of 32 gene mutations were available (27 mutations in KIT exon 11, 2 mutations in KIT exon 9, 1 mutation in PDGFRA exon 18, and 2 mutations with wild type). The remaining cases refused molecular typing and were unavailable for genetic data due to economic reasons. Adjuvant imatinib dose of $400 \mathrm{mg} / \mathrm{d}$ was administered to $42(42 / 118,35.6 \%)$ patients for a median time of 23 months (range, 9-46months). Part of patients with high-risk GISTs refused imatinib therapy because of economic reasons. The common toxicities for imatinib were palpebral edema, nausea, and leukopenia, which were well tolerated by patients. The clinicopathological characteristics of 118 patients are presented in Table 1. 
Table I Clinicopathological characteristics of II8 patients with gastric GISTs

\begin{tabular}{|c|c|}
\hline $\begin{array}{l}\text { Clinicopathological } \\
\text { characteristics }\end{array}$ & $\begin{array}{l}\text { Mean } \pm \text { SD }(\text { no. } / \%) \\
\text { patients }(N=103)\end{array}$ \\
\hline \multicolumn{2}{|l|}{ Gender (n, \%) } \\
\hline Male & $6 \mathrm{I}(5 \mathrm{I} .7)$ \\
\hline Female & $57(48.3)$ \\
\hline Age (years); Mean \pm SD & $55.66 \pm 12.47$ \\
\hline Tumor size, $\mathrm{cm}$; Mean $\pm \mathrm{SD}$ & $8.22 \pm 6.24$ \\
\hline \multicolumn{2}{|l|}{ Tumor location $(\mathrm{n}, \%)$} \\
\hline Upper third of stomach & $58(49.2)$ \\
\hline Middle third of stomach & $13(1 \mathrm{I} .0)$ \\
\hline Low third of stomach & $47(39.8)$ \\
\hline \multicolumn{2}{|l|}{ Mitotic counts (n, \%) } \\
\hline$\leq 5 / 50 \mathrm{HPF}$ & $50(42.4)$ \\
\hline 6-10/50 HPF & $35(29.7)$ \\
\hline$>10 / 50 \mathrm{HPF}$ & $33(28.0)$ \\
\hline \multicolumn{2}{|l|}{ Ki 67 (n, \%) } \\
\hline$<10 \%$ & $88(74.6)$ \\
\hline$\geq 10 \%$ & $30(25.4)$ \\
\hline CDII7 positive & $110(93.2)$ \\
\hline CD 34 positive & $106(89.8)$ \\
\hline DOG-I positive & $114(96.6)$ \\
\hline \multicolumn{2}{|l|}{ NIH risk classification ( $n, \%)$} \\
\hline Very low to low & $29(24.6)$ \\
\hline Intermediate to high & $89(75.4)$ \\
\hline \multicolumn{2}{|l|}{ CD55 expression } \\
\hline Negative & $74(62.7)$ \\
\hline Positive & $44(37.3)$ \\
\hline \multicolumn{2}{|l|}{ Metastasis at initial diagnosis ( $\mathrm{n}, \%)$} \\
\hline No & I0I (85.6) \\
\hline Yes & $17(14.4)$ \\
\hline Hospital stay, days; Mean \pm SD & $15.59 \pm 6.15$ \\
\hline Adjuvant IM therapy $(\mathrm{n}, \%)$ & $42(35.6)$ \\
\hline Median follow-up (range, months) & $67(4-110)$ \\
\hline
\end{tabular}

Abbreviations: GIST, gastrointestinal stromal tumors; HPF, high power field; NIH, National Institutes of Health.

\section{Associations between CD55 expression and clinicopathological characteristics}

The expression of CD55 in 118 gastric GISTs was investigated using immunohistochemistry staining. Positive features of CD55 expression were localized in the membrane of tumor cells (Figure 1). In this study, CD55 protein was observed to be positively expressed in $44(44 / 118,37.3 \%)$ of gastric GISTs. Table 2 indicates the association between CD55 expression and clinicopathological characteristics in gastric GISTs. The mean age of CD55-positive patients was significantly younger than that of CD55-negative patients (53.23 \pm 14.61 vs $57.11 \pm 10.86$ years, respectively; $P=0.039$ ). The CD55 expression in gastric GISTs was significantly associated with tumor size $(13.52 \pm 7.35$ vs $5.07 \pm 1.90 \mathrm{~cm}$, respectively; $P<0.001)$, Ki 67 labeling index $(P=0.001)$, mitotic counts $(P=0.005)$, NIH risk classification $(P<0.001)$, PLR $(P<0.001)$, and metastasis at initial diagnosis $(P=0.002)$. However, other clinicopathological characteristics such as gender, tumor location, NLR, adjuvant IM therapy, and hospital stay were not significantly correlated with CD55 expression. According to the Image-Pro Plus analysis results, the average IOD of CD55 was the highest in primary metastatic GISTs (tumor metastasis has occurred at the intimal diagnosis) and gradually defective in GISTs with metachronous metastasis, and GISTs without metastasis $(P<0.001)$ during the follow-up period, as shown in Figure 2 .

\section{Correlation between CD55 expression and tumor prognosis}

After a median follow-up time of 67 months (ranges, 4-110 months), the median PFS was 64 months (ranges, 6-110 months). However, the median OS was not reached. After the last follow-up, 29 patients experienced tumor progression, whereas 18 patients died due to tumor progression or other causes. Survival curves were drawn between CD55-negative and CD55-positive gastric GISTs (Figure 3). Kaplan-Meier analyses showed that patients with positive CD55 expression had significantly poorer PFS than those with negative expression $(P<0.001)$.

Univariate analysis of prognostic factors through Kaplan-Meier method showed that tumor size $(P<0.001)$, mitotic counts $(P<0.001)$, Ki 67 labeling index $(P<0.001)$, PLR $(P<0.001)$, metastasis at initial diagnosis $(P=0.031)$, and $\mathrm{CD} 55$ expression $(P<0.001)$ were statistically significant risk factors affecting PFS of patients with gastric GISTs (Table 3). To determine the independent prognostic factors, multivariate analyses were performed using the Cox proportional hazard model. Results showed that mitotic counts, Ki 67 labeling index, and CD55 expression were independent predictors of PFS for gastric GISTs.

\section{Discussion}

GISTs are common neoplasms of the gastrointestinal tract, the annual incidence of GISTs is about 10-15 cases per million. ${ }^{29}$ Unlike many other benign tumors, GISTs are heterogeneous with a broad clinical spectrum, ranging from indolent tumors to highly aggressive tumors 

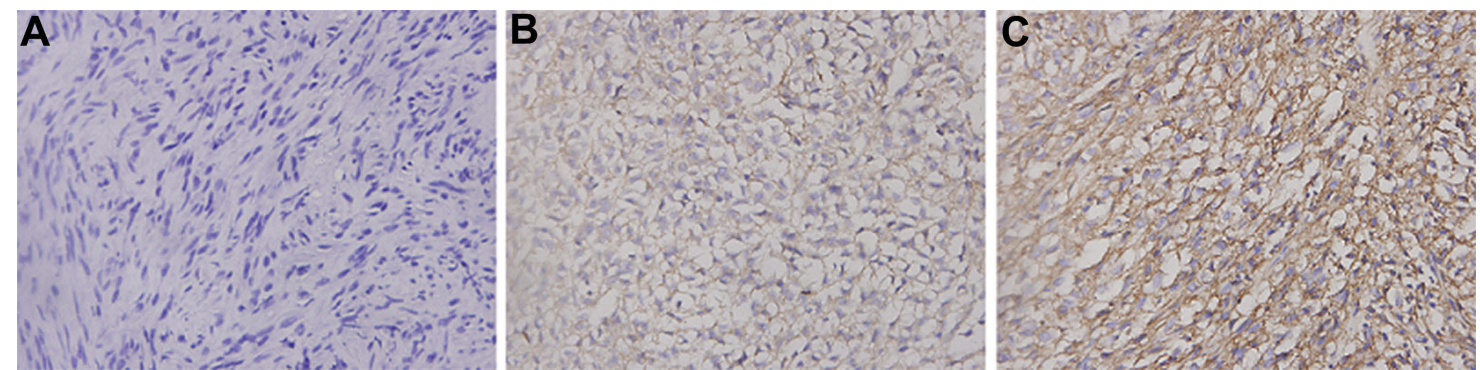

Figure I Representative immunohistochemical staining of CD55 in gastric GISTs (original magnification 400x).

Notes: (A) Absent or only weakly positive expression of CD55 in gastric GISTs without metastasis. (B, C) High expression of CD55 in gastric GISTs with metachronous metastasis and simultaneous metastasis, respectively.

Abbreviation: GISTs, gastrointestinal stromal tumors.

with extensive metastasis. ${ }^{30}$ Patients with advanced GISTs (metastatic or unresectable primary disease) have a poor clinical outcome, with a median survival of approximately 18 months. ${ }^{31}$ Because of most GISTs driven by activating mutations in KIT or PDGFRA, the use of TKI, such as imatinib, has been the backbone of therapy in both adjuvant and metastatic setting for GIST patients. Hence, several risk classification schemes were proposed to predict the biological behavior of GISTs and determine which patients should receive adjuvant imatinib treatment. However, these risk-stratification systems were all based on clinical parameters such as tumor location, mitotic count, and tumor size, which could not reveal the intrinsic mechanism of tumor progression in GISTs. The exact mechanism of progression in GISTs is still incompletely understood.

CD55 is a member of membrane-bound complement regulatory proteins, which was defined for the first time in $1969 .{ }^{32}$ Physiologically, CD55 is expressed in all cells exposing to the complement system, including red blood cells, leukocytes, endothelial cells, and epithelial cells. Moreover, soluble CD55 is detectable in body fluids and extracellular matrix. ${ }^{33}$ The most well-known function of CD55 is regulating the activation of the complement system by accelerating the decay of the $\mathrm{C} 3 / \mathrm{C} 5$-convertase of the classic and alternative pathways. Besides, CD55 has an inhibiting effect on natural killer cells. CD55 is also known as a receptor for certain viruses and microorganisms, and as a ligand of the CD97 receptor, which is a seven-span transmembrane receptor that is associated with cell-cell and cell-matrix adhesion. $^{34}$

Recently, CD55 has been detected in various kinds of malignant tumors such as colorectal cancer, gastric cancer, esophageal cancer, breast cancer, malignant glioma, thyroid cancer, medullary thyroid cancer, renal cancer, prostate cancer, ovarian cancer, cervical cancer, non-small cell lung cancer, nasopharyngeal cancer. Quantitative analysis of CD55 in the tumor environment showed that tumor cells have a 4-100fold increase in CD55 expression when compared to normal cells. ${ }^{35,36}$ It is reported that overexpression of CD55 is associated with malignancy and contributes to tumor invasion and metastases, leading to a poor prognosis. Durrant et al, ${ }^{22}$ retrospectively analyzed the correlation between CD55 expression and 7-year survival in 136 colorectal cancer patients, and found that patients with high levels of CD55 had a significantly worse survival than patients with low levels of CD55. Shen et $\mathrm{al}^{25}$ revealed that CD55 expression is positively associated with lymph node metastasis, distant metastasis, and clinical stage of nasopharyngeal carcinoma patients. However, the data on CD55 expression in GISTs have not been investigated until now.

In our previous study, we explored differential expression of proteins which might be responsible for gastric GISTs biologic progression by performing protein microarray analysis. We found that CD55 expression was significantly upregulated in high-grade malignant GISTs compared with low-grade ones. To investigate whether CD55 is involved in the progression of GISTs, we studied CD55 expression in 118 gastric GISTs tissue samples by immunohistochemistry, and analyzed the correlations of CD55 expression with clinicopathological characteristics and prognosis of gastric GISTs. Our results showed that CD55 expression in gastric GISTs was significantly associated with tumor size $(P<0.001)$, Ki 67 labeling index $(P=0.001)$, mitotic counts $(P=0.005)$, NIH risk classification $(P<0.001)$, and metastasis at initial diagnosis $(P=0.002)$, suggesting that 
Table 2 Correlation of CD55 expression with clinicopathological features of gastric GISTs

\begin{tabular}{|c|c|c|c|}
\hline \multirow[t]{2}{*}{ Variables } & \multicolumn{2}{|c|}{$\begin{array}{l}\text { CD55 expression, } \\
\text { n (\%) }\end{array}$} & \multirow[t]{2}{*}{$P$-value } \\
\hline & $\begin{array}{l}\text { Positive } \\
(n=44)\end{array}$ & $\begin{array}{l}\text { Negative } \\
(n=74)\end{array}$ & \\
\hline \multicolumn{4}{|l|}{ Gender (n, \%) } \\
\hline Male & $26(59.1)$ & $35(47.3)$ & 0.215 \\
\hline Female & $18(40.9)$ & $39(52.7)$ & \\
\hline Age (years); Mean \pm SD & $53.23 \pm|4.6|$ & $57.11 \pm 10.86$ & 0.039 \\
\hline $\begin{array}{l}\text { Tumor size, cm, Mean } \pm \\
\text { SD }\end{array}$ & $13.52 \pm 7.35$ & $5.07 \pm 1.90$ & $<0.001$ \\
\hline \multicolumn{4}{|l|}{ Tumor location (n, \%) } \\
\hline$U$ & $22(50.0)$ & $36(48.7)$ & 0.979 \\
\hline M & $5(11.4)$ & $8(10.8)$ & \\
\hline L & $17(38.6)$ & $30(40.5)$ & \\
\hline \multicolumn{4}{|l|}{ Ki 67 (n, \%) } \\
\hline$<10 \%$ & $25(58.6)$ & $63(85.1)$ & 0.001 \\
\hline$\geq 10 \%$ & $19(43.2)$ & II (I4.9) & \\
\hline \multicolumn{4}{|l|}{ Mitotic counts (n, \%) } \\
\hline$\leq 5 / 50 \mathrm{HPF}$ & $14(31.8)$ & $36(48.6)$ & 0.005 \\
\hline 6-10/50 HPF & $10(22.7)$ & $25(33.8)$ & \\
\hline$>10 / 50 \mathrm{HPF}$ & $20(45.5)$ & $13(17.6)$ & \\
\hline \multicolumn{4}{|l|}{$\begin{array}{l}\text { NIH risk classification } \\
(n, \%)\end{array}$} \\
\hline Very low to low & $2(4.5)$ & $27(36.5)$ & $<0.001$ \\
\hline Intermediate to high & $42(95.5)$ & $47(63.5)$ & \\
\hline \multicolumn{4}{|l|}{ NLR (n, \%) } \\
\hline Low NLR $(\leq 2.24)$ & $20(45.5)$ & $4 \mid(55.4)$ & 0.296 \\
\hline High NLR (>2.24) & $24(54.5)$ & $33(44.6)$ & \\
\hline \multicolumn{4}{|l|}{ PLR (n, \%) } \\
\hline Low PLR ( $(\leq|4| .29)$ & $14(31.8)$ & $55(74.3)$ & $<0.001$ \\
\hline High PLR (>|4|.29) & $30(68.2)$ & $19(25.7)$ & \\
\hline \multicolumn{4}{|l|}{$\begin{array}{l}\text { Metastasis at initial diag- } \\
\text { nosis }(n, \%)\end{array}$} \\
\hline No & $32(72.7)$ & $69(93.2)$ & 0.002 \\
\hline Yes & $12(27.3)$ & $5(6.8)$ & \\
\hline \multicolumn{4}{|l|}{ Adjuvant IM therapy (n, \%) } \\
\hline Yes & $13(29.5)$ & $29(39.2)$ & 0.290 \\
\hline No & $31(70.5)$ & $45(60.8)$ & \\
\hline $\begin{array}{l}\text { Hospital stay, days, Mean } \\
\pm \text { SD }\end{array}$ & $15.84 \pm 5.76$ & $15.45 \pm 6.90$ & 0.737 \\
\hline
\end{tabular}

Abbreviations: GIST, gastrointestinal stromal tumors; HPF, high power field; NIH, National Institutes of Health; L, lower third of stomach; M, middle third of stomach; $\mathrm{U}$, upper third of stomach.

CD55 may be a potential tumor promoter in the development and progression of gastric GISTs. When analyzing the correlation between PLR and CD55 expression,

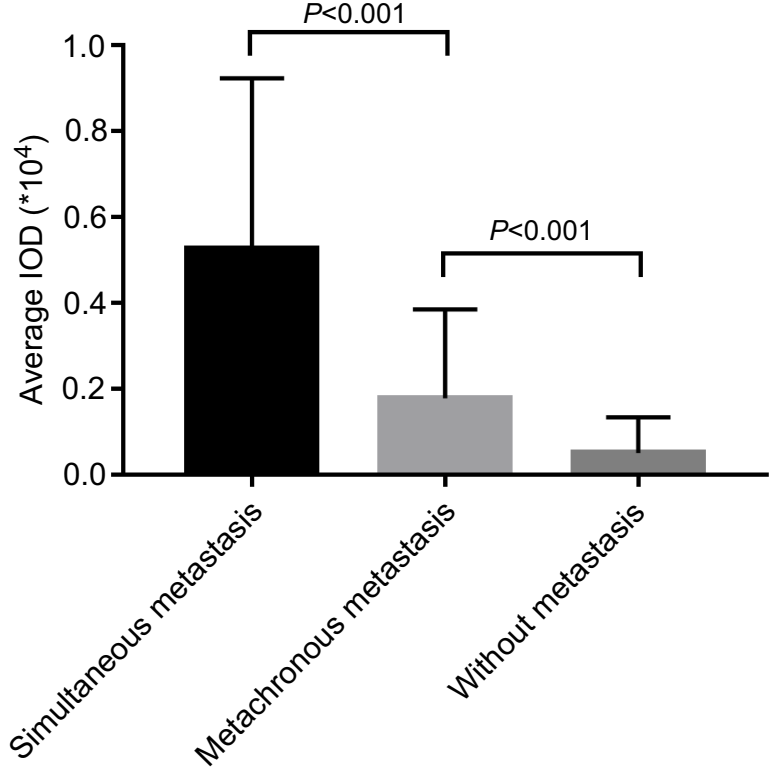

Figure 2 CD55 expression level was the highest in gastric GISTs with primary metastasis, and gradually defective in GISTs with metachronous metastases, and GISTs without metastasis $(P<0.00 I)$.

Abbreviation: GIST, gastrointestinal stromal tumors.

we found that the rate of high PLR in CD55-positive tumors was significantly higher than that of CD55negative tumors $(P<0.001)$. This result suggests that upregulation of CD55 expression in gastric GISTs may be associated with the reduction of peripheral blood lymphocyte counts, attributing to an enhanced systemic inflammatory response.

After the last follow-up, patients in our study were divided into three groups: patients with simultaneous metastasis (tumor metastasis has occurred at the initial diagnosis), patients with metachronous metastasis, and patients without metastasis. According to the ImagePro Plus analysis results, the average IOD of CD55 was highest in gastric GISTs with simultaneous metastasis, and gradually defective in that with metachronous metastasis, and without metastasis $(P<0.001)$. This result indicates that the overexpression of CD55 may be a possible marker for the metastatic potential of gastric GISTs patients. To explore the impact of CD55 expression on the prognosis of GIST patients, we plotted the survival curve of GISTs patients according to CD55 expression using the Kaplan-Meier method and log-rank test. The result showed that patients with positive CD55 expression had significantly poorer PFS than those with negative expression 
A

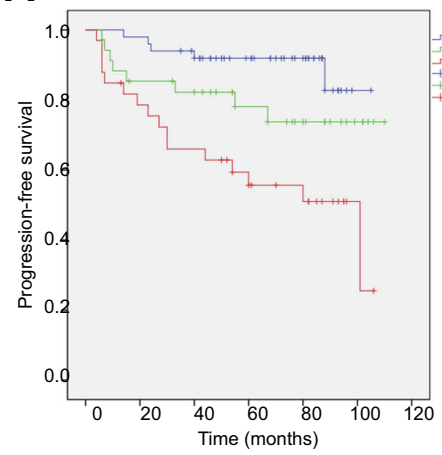

B

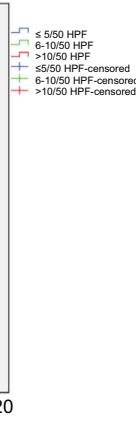

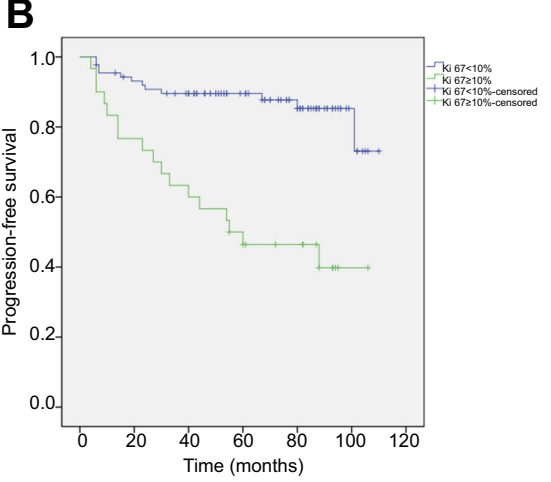

C

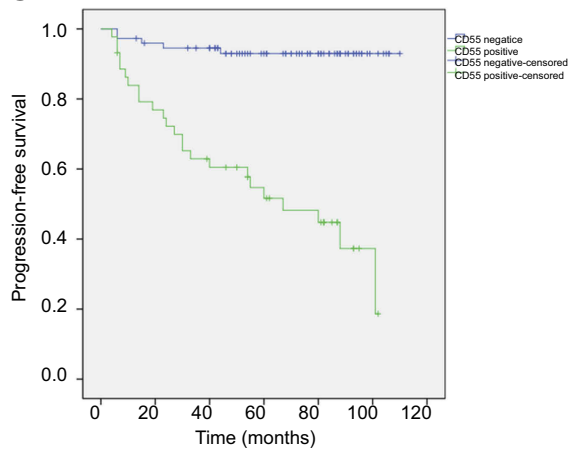

Figure 3 Kaplan-Meier survival curves of progression-free survival in patients with primary gastric GIST $(n=\mid 18)$.

Notes: (A) The tumors with mitotic counts $\leq 5 / 50$ HPF showed a significantly better PFS compared with these of $6-10 / 50 \mathrm{HPF}$ and $>10 / 50 \mathrm{HPF}(P<0.00 \mathrm{I})$. (B) The tumors with ki67 $<10 \%$ showed a significantly better PFS in comparison to those with ki67 $\geq 10 \%(P<0.001)$. (C) Patients with positive CD55 expression showed a significantly poorer progressive-free survival (PFS) than those with negative expression $(P<0.00 \mathrm{I})$.

Abbreviation: GIST, gastrointestinal stromal tumors.

$(P<0.001)$, suggesting that CD55 expression has potential value for predicting the prognosis of GIST patients. In addition, multivariate cox regression analysis showed that high mitotic counts (HR: 3.355, 95\%CI: 1.182-9.519; $P=0.023$ ), high Ki 67 labeling index (HR: 2.385, 95\%CI: $1.063-5.350 ; P=0.035)$, and positive CD55 expression (HR: 4.815, 95\%CI: 1.567-14.800; $P=0.006$ ) were independent risk factors of PFS for gastric GISTs. However, the exact mechanism of CD55 in tumorigenesis, invasion, and metastases is yet to be elucidated. It has been predicted that overexpression of CD55 by tumor cells might protect tumors from complement-mediated cell lysis and the deposition of $\mathrm{C} 3 \mathrm{~b}$, which leads to endocytosis by antigen-presenting cells. ${ }^{37}$ Furthermore, CD55 on tumor cells may promote tumor proliferation through activating the oncogenic tyrosine kinase pathway. Li et al, ${ }^{38}$ reported that CD55 is overexpressed within the stroma of colorectal tumors, suggesting that CD55 within the extracellular matrix is released from the cell membrane or secreted in a soluble form by MMP-7. Extracellular CD55 may inhibit the activation of complement system and specifically bind to CD97 for induction of cell migration. Additionally, studies have shown that overexpression of CD55 on K562 cells may make tumors more resistant to NK lysis. ${ }^{39}$

The majority of GISTs harbor oncogenic mutations in KIT or PDGFRA, and the application of TKIs significantly prolongs the survival in GIST patients. Unfortunately, most patients develop resistance to TKI therapy after several years of treatment, resulting in tumor progression. Treatment of progressive GISTs containing multiple resistant subclones remains a therapeutic challenge. Therefore, a novel molecular target needs to be developed to treat these progressive GISTs. Based on the presence and overexpression of CD55 in gastric GISTs, CD55 may serve as a potential target for molecular targeting therapy of GISTs. The anti-CD55 monoclonal antibody SC-1 has been identified to bind CD55 which is expressed in gastric carcinoma, resulting in apoptosis of tumor cells. ${ }^{40}$ Illert et $\mathrm{al},{ }^{41}$ reported that treatment with $\mathrm{SC}-1$ in nude mice with metastatic gastric cancer could remarkably reduce the number of disseminated tumor cells in the bone marrow. The toxicity of SC-1 has been reported that is comprehensively low and tolerable. ${ }^{42}$ In addition, the application of CD55 as a target for immunotherapy could enhance tumor killing, T-cell infiltration, and NK activity within the tumors of immunized patients. A human monoclonal antiidiotypic antibody, 105AD7, which mimics the antigen, CD55, has been developed. Studies have shown that 105AD7 is able to stimulate T-cell responses and NK activity in vitro and in vivo. ${ }^{43-46}$ Hence, bispecific antibodies binding CD55 as well as another tumor-specific antigen KIT might be a solution to improve the therapeutic efficacy and decrease unwanted side effects in GISTs.

\section{Conclusion}

In conclusion, this is the first study to investigate the role of CD55 expression in patients with gastric GIST. Our study indicated that patients with positive CD55 expression had a significantly poorer PFS than those with negative CD55 expression. Our study demonstrated that CD55 may be a potential prognostic marker and 
Table 3 Univariate and multivariate analysis of PFS in patients with GIST

\begin{tabular}{|c|c|c|c|}
\hline \multirow[t]{2}{*}{ Variables } & \multirow{2}{*}{$\begin{array}{l}\text { Univ- } \\
\text { ariate } \\
\text { analy- } \\
\text { sis }\end{array}$} & \multicolumn{2}{|c|}{ Multivariate analysis } \\
\hline & & HR (95\% Cl) & $\begin{array}{l}P \text {-val- } \\
\text { ue }\end{array}$ \\
\hline $\begin{array}{l}\text { Tumor size } \\
\qquad 5 \mathrm{~cm} \\
>5 \mathrm{~cm}\end{array}$ & $<0.001$ & $\begin{array}{l}\text { Reference } \\
\text { I.485 (0.458-4.816) }\end{array}$ & 0.510 \\
\hline $\begin{array}{l}\text { Tumor location } \\
\text { U } \\
M \\
L\end{array}$ & 0.179 & - & \\
\hline $\begin{array}{l}\text { Mitotic counts } \\
\leq 5 / 50 \mathrm{HPF} \\
6-10 / 50 \mathrm{HPF} \\
>10 / 50 \mathrm{HPF}\end{array}$ & $<0.001$ & $\begin{array}{l}\text { Reference } \\
2.74 I(0.860-8.7381) \\
3.355(1.182-9.519)\end{array}$ & $\begin{array}{l}0.088 \\
0.023\end{array}$ \\
\hline $\begin{array}{rl}K i & 67 \\
& <10 \% \\
\geq 10 \%\end{array}$ & $<0.001$ & $\begin{array}{l}\text { Reference } \\
2.385(1.063-5.350)\end{array}$ & 0.035 \\
\hline $\begin{array}{l}\text { NLR } \\
\text { Low NLR }(\leq 2.24) \\
\text { High NLR }(>2.24)\end{array}$ & 0.300 & - & \\
\hline $\begin{array}{l}\text { PLR } \\
\qquad \text { Low PLR ( } \leq|4| .29) \\
\text { High PLR }(>|4| .29)\end{array}$ & $<0.001$ & $\begin{array}{l}\text { Reference } \\
2.299(0.962-5.493)\end{array}$ & 0.061 \\
\hline $\begin{array}{l}\text { Metastasis at initial } \\
\text { diagnosis } \\
\text { No } \\
\text { Yes }\end{array}$ & 0.031 & $\begin{array}{l}\text { Reference } \\
0.826(0.325-2.099)\end{array}$ & 0.687 \\
\hline $\begin{array}{l}\text { CD55 expression } \\
\text { Negative } \\
\text { Positive }\end{array}$ & $<0.001$ & $\begin{array}{l}\text { Reference } \\
4.815(1.567-14.800)\end{array}$ & 0.006 \\
\hline $\begin{array}{l}\text { Adjuvant IM therapy } \\
\text { Yes } \\
\text { No }\end{array}$ & 0.424 & - & \\
\hline
\end{tabular}

Abbreviations: $\mathrm{Cl}$, confidential interval; GIST, gastrointestinal stromal tumors; HPF, high power field; HR, hazard ratio; PFS, progression-free survival.

therapeutic target in gastric GISTs. Further studies investigating the exact mechanism of CD55 in gastric GISTs are warranted.

\section{Abbreviations}

GIST, gastrointestinal stromal tumor; PDGFRA, plateletderived growth factor receptor- $\alpha$; TKI, tyrosine kinase inhibitor; PFS, progression-free survival; OS, overall survival;
DAF, decay accelerating factor; GPI, glycosylphosphatidylinositol; NIH, National Institutes of Health; NLR, neutrophil-to-lymphocyte ratio; PLR, platelet-to-lymphocyte ratio; IOD, integral optical density; CT, computed tomography; $\mathrm{SD}$, standard deviation.

\section{Acknowledgments}

The authors gratefully acknowledge all the staff of the Department of Gastrointestinal Surgery and Pathology, West China Hospital, who generously provided invaluable assistance in the collection of data throughout the duration of the study. This study was funded by the National Natural Science Foundation of China (grant agreement number 81572931). The abstract of this paper was presented at the Korea International Gastric Cancer Week 2018 Conference name PP10-4 as a poster presentation with interim findings.

\section{Disclosure}

The authors report no conflicts of interest in this work.

\section{References}

1. Corless CL, Barnett CM, Heinrich MC. Gastrointestinal stromal tumours: origin and molecular oncology. Nat Rev Cancer. 2011;11 (12):865-878. doi:10.1038/nrc3143

2. Heinrich MC, Corless CL, Duensing A, et al. PDGFRA activating mutations in gastrointestinal stromal tumors. Science. 2003;299 (5607):708-710. doi:10.1126/science.1079666

3. Hirota S, Isozaki K, Moriyama Y, et al. Gain-of-function mutations of c-kit in human gastrointestinal stromal tumors. Science. 1998;279 (5350):577-580.

4. Al-Thani H, El-Menyar A, Rasul KI, et al. Clinical presentation, management and outcomes of gastrointestinal stromal tumors. Int J Surg. 2014;12(10):1127-1133. doi:10.1016/j.ijsu.2014.08.351

5. Joensuu H, Fletcher C, Dimitrijevic S, Silberman S, Roberts P, Demetri G. Management of malignant gastrointestinal stromal tumours. Lancet Oncol. 2002;3(11):655-664. doi:10.1016/S14702045(02)00899-9

6. Joensuu H, Eriksson M, Sundby Hall K, et al. One vs three years of adjuvant imatinib for operable gastrointestinal stromal tumor: a randomized trial. JAMA. 2012;307(12):1265-1272. doi:1210.1001/ jama.2012.1347

7. Verweij J, Casali PG, Zalcberg J, et al. Progression-free survival in gastrointestinal stromal tumours with high-dose imatinib: randomised trial. Lancet. 2004;364(9440):1127-1134. doi:1110.1016/S01406736(1104)17098-17090

8. Gold JS, Gonen M, Gutierrez A, et al. Development and validation of a prognostic nomogram for recurrence-free survival after complete surgical resection of localised primary gastrointestinal stromal tumour: a retrospective analysis. Lancet Oncol. 2009;10 (11):1045-1052. doi:10.1016/S1470-2045(09)70242-6

9. Joensuu H. Risk stratification of patients diagnosed with gastrointestinal stromal tumor. Hum Pathol. 2008;39(10):1411-1419. doi:10.1016/j.humpath.2008.06.025

10. Joensuu H, Vehtari A, Riihimaki J, et al. Risk of recurrence of gastrointestinal stromal tumour after surgery: an analysis of pooled population-based cohorts. Lancet Oncol. 2012;13(3):265-274. doi:10.1016/S1470-2045(11)70299-6 
11. Miettinen M, Sobin LH, Lasota J. Gastrointestinal stromal tumors of the stomach: a clinicopathologic, immunohistochemical, and molecular genetic study of 1765 cases with long-term follow-up. Am J Surg Pathol. 2005;29(1):52-68.

12. Geddert H, Braun A, Kayser C, et al. Epigenetic regulation of CD133 in gastrointestinal stromal tumors. Am J Clin Pathol. 2017;147 (5):515-524. doi:10.1093/ajcp/aqx028

13. Liu N, Huang J, Sun S, et al. Expression of matrix metalloproteinase-9, cyclooxygenase-2 and vascular endothelial growth factor are increased in gastrointestinal stromal tumors. Int J Clin Exp Med. 2015;8(4):6495-6501.

14. $\mathrm{Lu} \mathrm{C}$, Liu L, Wu X, Xu W. CD133 and Ki-67 expression is associated with gastrointestinal stromal tumor prognosis. Oncol Lett. 2013;6 (5):1289-1294. doi:10.3892/ol.2013.1564

15. Merten L, Agaimy A, Moskalev EA, et al. Inactivating mutations of RB1 and TP53 correlate with sarcomatous histomorphology and metastasis/recurrence in gastrointestinal stromal tumors. Am J Clin Pathol. 2016;146(6):718-726. doi:10.1093/ajcp/aqw193

16. Neves LR, Oshima CT, Artigiani-Neto R, Yanaguibashi G, Lourenco LG, Forones NM. Ki67 and p53 in gastrointestinal stromal tumors-GIST. Arq Gastroenterol. 2009;46(2):116-120.

17. Quattrone A, Wozniak A, Dewaele B, et al. Frequent mono-allelic loss associated with deficient PTEN expression in imatinib-resistant gastrointestinal stromal tumors. Mod Pathol. 2014;27 (11):1510-1520. doi:10.1038/modpathol.2014.53

18. Wallander ML, Layfield LJ, Tripp SR, Schmidt RL. Gastrointestinal stromal tumors: clinical significance of p53 expression, MDM2 amplification, and KIT mutation status. Appl Immunohistochem Mol Morphol. 2013;21(4):308-312. doi:10.1097/PAI.0b013e31826ea7c0

19. Yang H, Shen C, Zhang B, Chen H, Chen Z, Chen J. Expression and clinicopathological significance of CD9 in gastrointestinal stromal tumor. J Korean Med Sci. 2013;28(10):1443-1448. doi:10.3346/ jkms.2013.28.10.1443

20. Zhou Y, Hu W, Chen $\mathrm{P}$, et al. Ki67 is a biological marker of malignant risk of gastrointestinal stromal tumors: a systematic review and meta-analysis. Medicine. 2017;96(34):e7911. doi:10.1097/ MD.0000000000007911

21. Shen C, Yin Y, Chen $\mathrm{H}$, et al. Secreted protein acidic and rich in cysteine-like 1 suppresses metastasis in gastric stromal tumors. BMC Gastroenterol. 2018;18(1):105. doi:110.1186/s12876-12018-1083312878

22. Durrant LG, Chapman MA, Buckley DJ, Spendlove I, Robins RA, Armitage NC. Enhanced expression of the complement regulatory protein CD55 predicts a poor prognosis in colorectal cancer patients Cancer Immunol Immuno Ther. 2003;52(10):638-642. Epub 02003 Jun 00214. doi: 610.1007/s00262-00003-00402-y

23. Ikeda J, Morii E, Liu Y, et al. Prognostic significance of CD55 expression in breast cancer. Clin Cancer Res. 2008;14 (15):4780-4786. doi:4710.1158/1078-0432.CCR-4707-1844

24. Loberg RD, Wojno KJ, Day LL, Pienta KJ. Analysis of membrane-bound complement regulatory proteins in prostate cancer. Urology. 2005;66(6):1321-1326. doi:1310.1016/j. urology.2005.1306.1094

25. Shen Y, Yin R, Deng X, Shen H. Increased expression of CD55 correlates with tumor progression and poor prognosis in nasopharyngeal carcinoma. Clin Invest Med. 2012;35(1):E34-E39.

26. Inoue T, Yamakawa M, Takahashi T. Expression of complement regulating factors in gastric cancer cells. Mol Pathol. 2002;55 (3):193-199.

27. Madjd Z, Durrant LG, Bradley R, Spendlove I, Ellis IO, Pinder SE. Loss of CD55 is associated with aggressive breast tumors. Clin Cancer Res. 2004;10(8):2797-2803.

28. Feng F, Tian Y, Liu S, et al. Combination of PLR, MLR, MWR, and tumor size could significantly increase the prognostic value for gastrointestinal stromal tumors. Medicine (Baltimore). 2016;95(14): e3248. doi:3210.1097/MD.0000000000003248
29. Demetri GD, von Mehren M, Antonescu CR, et al. NCCN task force report: update on the management of patients with gastrointestinal stromal tumors. J National Compr Cancer Network. 2010;8(Suppl 2):S1-S41. quiz S42-44.

30. Muenst S, Thies S, Went P, Tornillo L, Bihl MP, Dirnhofer S. Frequency, phenotype, and genotype of minute gastrointestinal stromal tumors in the stomach: an autopsy study. Hum Pathol. 2011;42 (12):1849-1854. doi:10.1016/j.humpath.2011.01.024

31. DeMatteo RP, Lewis JJ, Leung D, Mudan SS, Woodruff JM, Brennan MF. Two hundred gastrointestinal stromal tumors: recurrence patterns and prognostic factors for survival. Ann Surg. 2000;231(1):51-58.

32. Hoffman EM, Seya T, Kojima A, et al. Inhibition of complement by a substance isolated from human erythrocytes. I. Extraction from human erythrocyte stromata enhancement of lymphocyte-mediated K562 cytotoxicity by antibodies against complement membrane cofactor protein (CD46) and decay-accelerating factor (CD55). Immunochemistry. 1969;6(3):391-403.

33. Mikesch JH, Schier K, Roetger A, Simon R, Buerger H, Brandt B. The expression and action of decay-accelerating factor (CD55) in human malignancies and cancer therapy. Cell Oncol. 2006;28 (5-6):223-232.

34. Mikesch JH, Buerger H, Simon R, Brandt B. Decay-accelerating factor (CD55): a versatile acting molecule in human malignancies. Biochim Biophys Acta. 2006;1766(1):42-52.

35. Nicholson-Weller A. Decay accelerating factor (CD55). Curr Top Microbiol Immunol. 1992;178:7-30.

36. Yan J, Allendorf DJ, Li B, Yan R, Hansen R, Donev R. The role of membrane complement regulatory proteins in cancer immunotherapy. Adv Exp Med Biol. 2008;632:159-174.

37. Spendlove I, Li L, Carmichael J, Durrant LG. Decay accelerating factor (CD55): a target for cancer vaccines? Cancer Res. 1999;59 (10):2282-2286.

38. Li L, Spendlove I, Morgan J, Durrant LG. CD55 is over-expressed in the tumour environment. $\mathrm{Br} J$ Cancer. 2001;84(1):80-86. doi:10.1054/ bjoc. 2000.1570

39. Jurianz K, Ziegler S, Donin N, Reiter Y, Fishelson Z, Kirschfink M. K562 erythroleukemic cells are equipped with multiple mechanisms of resistance to lysis by complement. Int $J$ Cancer. 2001;93(6):848-854.

40. Hensel F, Hermann R, Brandlein S, et al. Regulation of the new coexpressed CD55 (decay-accelerating factor) receptor on stomach carcinoma cells involved in antibody SC-1-induced apoptosis. Lab Invest. 2001;81(11):1553-1563. doi:10.1038/labinvest.3780369

41. Illert B, Otto C, Vollmers HP, Hensel F, Thiede A, Timmermann W. Human antibody SC-1 reduces disseminated tumor cells in nude mice with human gastric cancer. Oncol Rep. 2005;13(4):765-770.

42. Dygai AM, Sherstoboev E, Gol'Dberg ED. [The role of SC-1(+)- and Thy-1(+)-cells in the regulation of cytokine production by cells of the bone marrow regenerating after cytostatic action]. Biull Eksp Biol Med. 1998;125(4):374-377.

43. Buckley DT, Robins AR, Durrant LG. Clinical evidence that the human monoclonal anti-idiotypic antibody 105AD7, delays tumor growth by stimulating anti-tumor T-cell responses. Hum Antibodies Hybridomas. 1995;6(2):68-72.

44. Durrant LG, Buckley DJ, Robins RA, Spendlove I. 105Ad7 cancer vaccine stimulates anti-tumour helper and cytotoxic T-cell responses in colorectal cancer patients but repeated immunisations are required to maintain these responses. Int J Cancer. 2000;85(1):87-92.

45. Durrant LG, Maxwell-Armstrong C, Buckley D, et al. A neoadjuvant clinical trial in colorectal cancer patients of the human anti-idiotypic antibody 105AD7, which mimics CD55. Clin Cancer Res. 2000;6(2):422-430.

46. Maxwell-Armstrong CA, Durrant LG, Buckley TJ, et al. Randomized double-blind phase II survival study comparing immunization with the anti-idiotypic monoclonal antibody 105AD7 against placebo in advanced colorectal cancer. Br J Cancer. 2001;84(11):1443-1446. doi:10.1054/ bjoc. 2001.1725 


\section{Supplementary material}

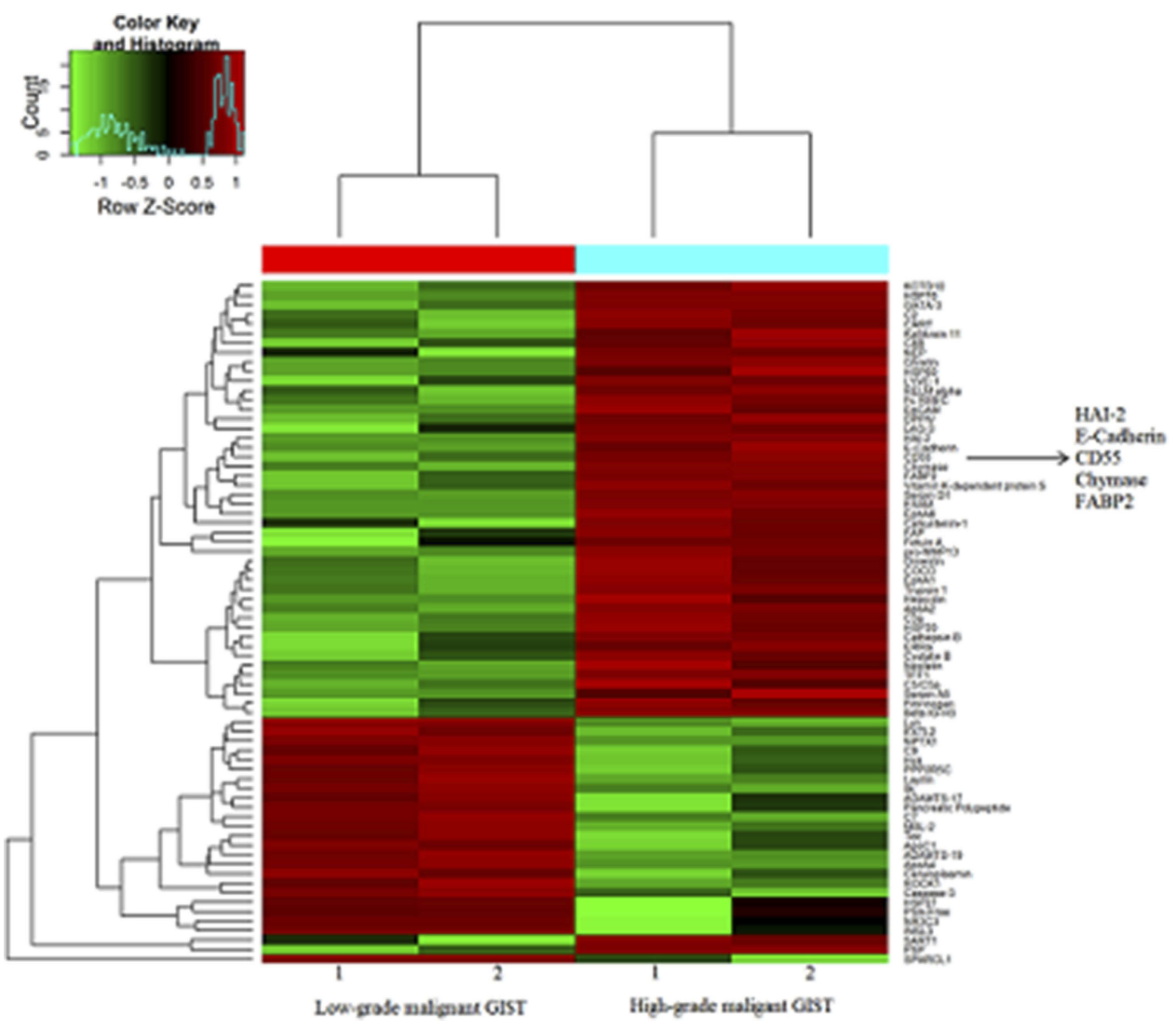

Figure SI Hierarchical cluster analysis of data between low-malignant GISTs and high-malignant GISTs. Each column represents a single tissue specimen, and each horizontal line refers to a protein. Color legends are on the top of the figures. Red indicates a high expression, green indicates a low expression, and black indicates a mean expression.

Abbreviation: GIST, gastrointestinal stromal tumors.

\section{Publish your work in this journal}

OncoTargets and Therapy is an international, peer-reviewed, open access journal focusing on the pathological basis of all cancers, potential targets for therapy and treatment protocols employed to improve the management of cancer patients. The journal also focuses on the impact of management programs and new therapeutic agents and protocols on patient perspectives such as quality of life, adherence and satisfaction. The manuscript management system is completely online and includes a very quick and fair peer-review system, which is all easy to use. Visit http://www.dovepress.com/ testimonials.php to read real quotes from published authors. 